\title{
Microstructure and Electrochemical Properties of CoCrCuFeNiNb High-Entropy Alloys Coatings
}

\author{
Jiangbo Cheng $\cdot$ Dan Liu $\cdot$ Xiubing Liang $\cdot$ Binshi Xu
}

Received: 25 July 2013/Revised: 23 January 2014/Published online: 5 August 2014

(C) The Chinese Society for Metals and Springer-Verlag Berlin Heidelberg 2014

\begin{abstract}
The CoCrCuFeNiNb high-entropy alloys coatings were prepared by using plasma-transferred arc cladding process. The microstructure and electrochemical behaviors of the coating were investigated in detail. The experimental results indicated that the coating consists of a simple fcc solid solution phase and an order $(\mathrm{CoCr}) \mathrm{Nb}$-type Laves phase. The polarization curves, obtained in 1 and $6 \mathrm{~mol} / \mathrm{L}$ hydrochloric acid solutions, clearly indicated that the general corrosion resistance of the coating at ambient temperature was better than that of 304 stainless steel. The coating displayed a lower corrosion current and lower corrosion rate. Electrochemical impedance spectroscopy demonstrated that the impedance of the coating was significantly higher than that of the 304 stainless steel.
\end{abstract}

KEY WORDS: CoCrCuFeNiNb; High-entropy alloy; Coating; Corrosion behavior

\section{Introduction}

Since the multiple-element system was proposed by Yeh et al. [1], high-entropy alloys (HEAs) have been attracted great attention owing to their outstanding properties, such as high strength/hardness [2], outstanding wear and corrosion resistance [3], exceptional high temperature strength/hardness $[4,5]$, and high structural and chemical stabilities at high temperature [6]. The coating technologies are further expanding their range of application, including the hard-facing of golf heads and rollers, diffusion barriers, and soft magnetic films [7-9].

Available online at http://link.springer.com/journal/40195

J. Cheng $(\bowtie) \cdot$ D. Liu

College of Mechanics and Materials, Hohai University, Nanjing 210098, China

e-mail: chengjiangbo@ hotmail.com

J. Cheng $\cdot$ X. Liang $\cdot$ B. Xu

National Key Laboratory for Remanufacturing, Beijing 100072,

China
Recently, there has been an increasing interest in producing HEAs coatings by different surface engineering technologies. Yeh et al. [1] investigated the nitride and oxide coatings based on HEAs targets by DC or RF reactive magnetron sputtering. Reported high-entropy alloys such as (AlCrTaTiZr) $\mathrm{N}_{x}$ [10], (AlCrSiTiV)N $\mathrm{N}_{x}$ [11], (Al$\mathrm{CrMoSiTi}_{x}$ [12], (AlMoNbSiTaTiVZr)N ${ }_{x}$ [13], (Al-

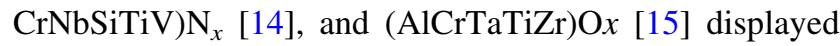
high hardness spanning from 8 to $41 \mathrm{GPa}$. For thermal spraying process, $\mathrm{Al}(\mathrm{Co}) \mathrm{CrFeMo} 0.5 \mathrm{NiSiTi}$ alloy powders have been converted to protective coatings by atmosphere plasma spraying, exhibiting high oxidation resistance and wear resistance [16]. Wang et al. [17] prepared $\mathrm{Ni}_{x} \mathrm{Co}_{0.6}$ $\mathrm{Fe}_{0.2} \mathrm{Cr}_{y} \mathrm{Si}_{z} \mathrm{AlTi}_{0.2}$ coating by using plasma spraying process. After heat treatment, large amounts of nanoscale particles exist in the matrix. The coating has high hardness and excellent coarsening resistance performance. Tungsten inert gas (TIG) cladding process was successfully used to fabricate $\mathrm{FeCoCrNiMo}_{x}$ multi-element alloy coatings [18]. Several HEAs, such as $6 \mathrm{FeNiCoSiCrAl}, \mathrm{CoNiCuFeCr}$, and $\mathrm{Al}_{x} \mathrm{FeCoNiCuCr}$, have been coated by laser cladding [1921]. However, the microstructure and properties of the alloys display strong dependence on the composition. In 
$\mathrm{FeCoNiCrCu}_{x}$ alloys, the volume fractions of fcc phase increased, and corrosion resistance decreased as $\mathrm{Cu}$ content increased [22]. In previous work [23], the CoCrCuFeNi HEAs coatings were prepared by plasma-transferred arc (PTA) cladding process. The coating displayed excellent corrosion resistance which was better than that of 304 stainless steel (304 SS) in $1 \mathrm{~mol} / \mathrm{L}$ hydrochloric acid solution. So far, it is not clarified; however, whether there is a relationship between the structure of the alloying elements and that of the HEAs. In order to understand the behavior of HEAs in a better way, new compositions are being developed by employing different synthesis routes and using more sensitive tools for their characterization.

In the present study, $\mathrm{CoCrCuFeNiNb}$ HEAs coatings were synthesized by PTA cladding process. The structure of the coating was investigated. The electrochemical properties of the coating were investigated in detail.

\section{Experimental}

The equi-atomic $\mathrm{Co}, \mathrm{Cr}, \mathrm{Cu}, \mathrm{Fe}, \mathrm{Ni}$, and $\mathrm{Nb}$ of the powder mixture were prepared by mechanically mixing commercial metal powders (purity is higher than $99.7 \mathrm{wt} \%$ ). The particle sizes of the powders were in the range of 50-150 $\mu \mathrm{m}$. The substrate was Q235 steel, which composition (wt\%) is $0.18 \mathrm{C}, 0.22 \mathrm{Si}, 0.60 \mathrm{Mn}, 0.02 \mathrm{~S}, 0.016 \mathrm{P}$, and balance of $\mathrm{Fe}$. The grinding wheel was employed to remove oxide skin and increase roughness of the substrate, and then the substrate was degreased by acetone and dried in air. The mixed powders were pre-placed onto the surface of Q235 steel substrate by using glue to form powder bed with the thickness of $1.8-2.0 \mathrm{~mm}$. Before cladding, the prefabrication samples were dried in drying box at $100{ }^{\circ} \mathrm{C}$ for $4 \mathrm{~h}$. A PTA gun system was employed for coatings preparation. The diameter of the nozzle is $12 \mathrm{~mm}$. The PTA cladding parameters used in this research are listed as follows: voltage was $30 \mathrm{~V}$, current was $180 \mathrm{~A}$, travel speed of the nozzle was $55 \mathrm{~mm} / \mathrm{min}$, working Ar flow rate was $1.6 \mathrm{~L} / \mathrm{min}$, shrouding Ar flow rate was $2.4 \mathrm{~L} / \mathrm{min}$, and distance between torch and substrate was $30 \mathrm{~mm}$.

After the PTA cladding, the specimen was sectioned perpendicular to the scanning track with a wire-EDM machine. The samples were polished and etched with aqua regia (nitro-hydrochloric acid) for observation under the S3400 scanning electron microscope (SEM). The chemical compositions of the coating were analyzed by SEM equipped energy dispersive spectrometry (EDS). Phase structures of the coatings were determined by X-ray diffraction $(\mathrm{XRD})$ with $\mathrm{Cu} K_{\alpha}(\lambda=0.154 \mathrm{~nm})$ radiation at a step of $0.02^{\circ}$ on the D8-Advance apparatus.

For corrosion tests, specimens were wet ground to P2000 finish, degreased in isopropyl alcohol in an

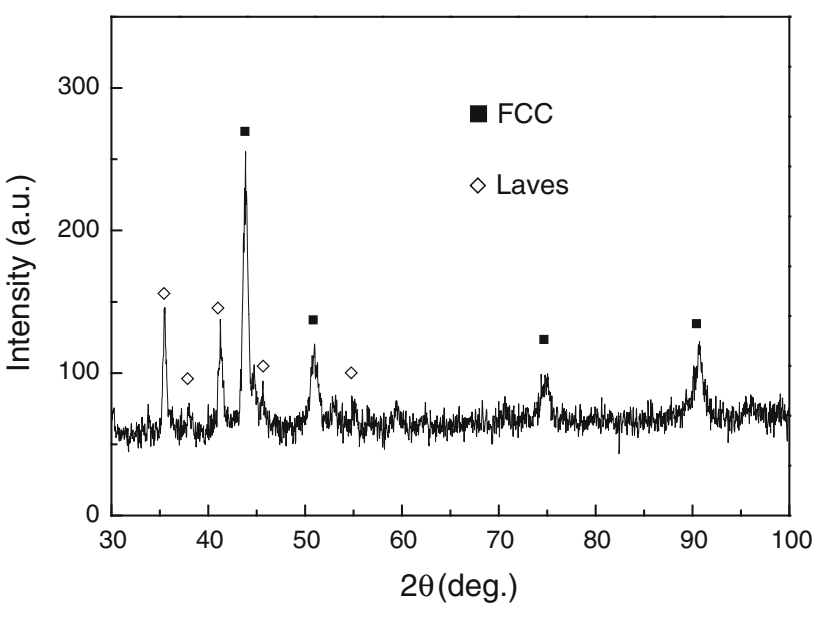

Fig. 1 XRD pattern of the coating

ultrasonic bath, and dried by hot dry air. Electrochemical measurements were performed using an electrochemical cell, where an area of $1 \mathrm{~cm}^{2}$ of the studied specimens was exposed to the naturally aerated 1 and $6 \mathrm{~mol} / \mathrm{L}$ hydrochloric acid solutions at room temperature $\left(25^{\circ} \mathrm{C}\right)$. Electrochemical tests were conducted via the Parstat 2273 advanced potentiostat with a traditional three electrode system. The system contains a saturated calomel reference electrode (SCE) and a Pt counter electrode. Two kinds of electrochemical tests, namely potentiodynamic polarization test and electrochemical impendence spectroscopy test (EIS), were carried out to compare corrosion resistance of HEAs coatings and 304 SS. Potentiodynamic polarization curves were measured with a potential sweep rate of $0.5 \mathrm{mV} / \mathrm{s}$ in 1 and $6 \mathrm{~mol} / \mathrm{L}$ hydrochloric acid solution open to air at $25{ }^{\circ} \mathrm{C}$ after immersing for $0.5 \mathrm{~h}$, when the opencircuit potential became steady. The frequency range of EIS tests was from $10 \mathrm{kHz}$ to $10 \mathrm{mHz}$, and the amplitude of sinusoidal potential signal was $5 \mathrm{mV}$ with respect to the open circuit potential. All measurements were repeated at least thrice to see if the surface behavior was reproducible.

\section{Results and Discussion}

\subsection{Structure}

Figure 1 shows the XRD pattern of the coating. It can be seen that the coating consists of fcc solid solution phase and Laves phase. The Laves phase can be identified as (CoCr) $\mathrm{Nb}$ type with an hcp phase structure. Furthermore, the intensity of the Laves phase is evidently lower than that of the fcc solid solution phase, indicating that the main phase is the latter one. The reason for this is ascribed to the high-mixture entropy effect that greatly lowers the Gibbs 


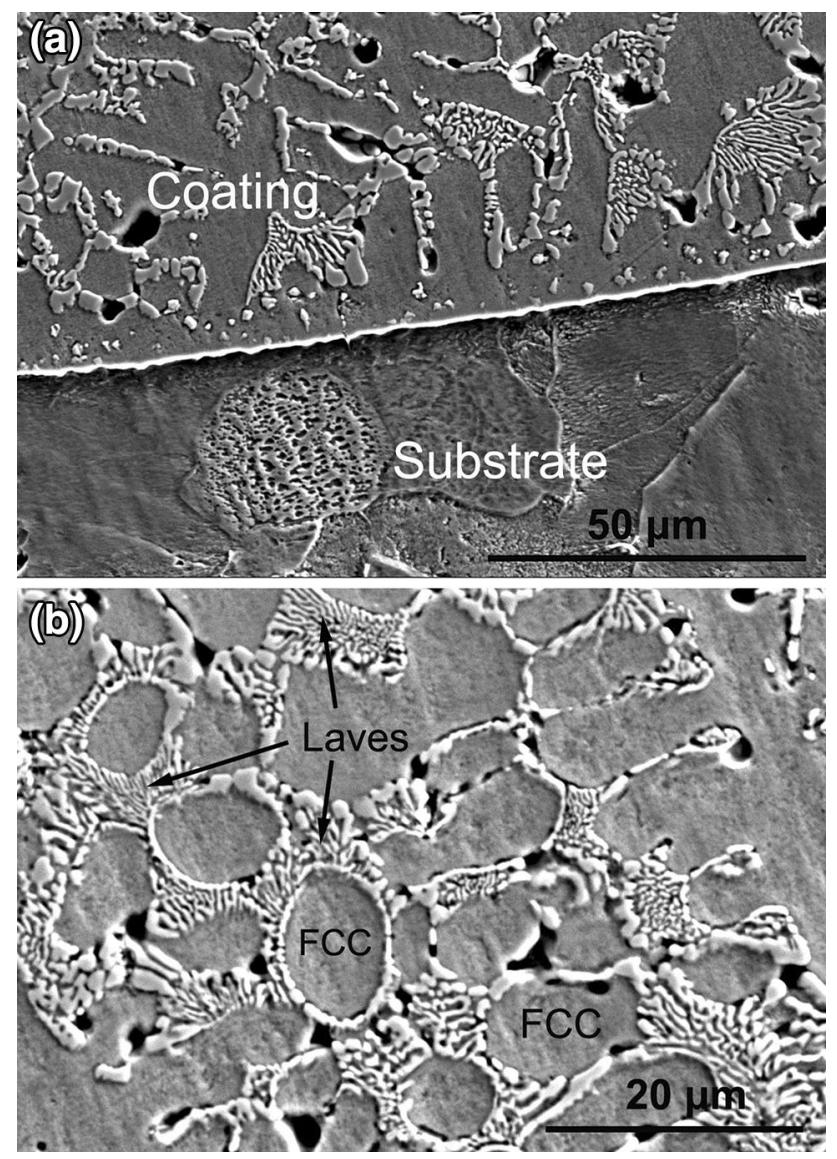

Fig. 2 SEM images of the sample: a cross section; $\mathbf{b}$ surface of the $\mathrm{CoNiCuFeCrNb}$ coating

free energy of the system, is more easy for solid solutions formation during solidification, rather than ordered compounds especially at the high temperature, and leads to the total number of the phases well below the maximum equilibrium number allowed by the Gibbs phase rule [1]. In addition, the lattice parameters of fcc solid solution from the strongest $\left(\begin{array}{lll}1 & 0 & 0\end{array}\right)$ peak are estimated to be $0.3593 \mathrm{~nm}$.

Figure 2 shows the microstructure morphologies of the coating. The cross-sectional SEM image of the coating is shown in Fig. 2a. The rapid directional solidification can be observed at the fusion region of the coating where the growth direction of the columnar grains was perpendicular to the interface. At the fusion zone of the weld pool, the interface was marked by a featureless zone which was formed by solidification with a plane solid-liquid interface. This interface appeared at the bottom of the melt pool due to the large ratio $(G / V)$ between the temperature gradient $(G)$ at the solid-liquid interface and the solidification rate $(V)$. This ratio decreased rapidly as the solidification front progressed to the specimen surface, causing a transition from plane front solidification to cellular and, eventually, to dendritic solidification [24]. The morphology had a
Table 1 Chemical compositions of the different region in the coating (in at \%)

\begin{tabular}{lllllrr}
\hline Region & $\mathrm{Fe}$ & $\mathrm{Co}$ & $\mathrm{Ni}$ & $\mathrm{Cr}$ & $\mathrm{Cu}$ & \multicolumn{1}{c}{$\mathrm{Nb}$} \\
\hline Dendrite & 28.69 & 17.26 & 16.62 & 17.10 & 15.25 & 3.09 \\
Interdendrite & 17.51 & 14.89 & 17.25 & 13.84 & 6.90 & 29.61 \\
\hline
\end{tabular}

strong dependence on $G / V$ during solidification. The $V$ increased when the distance away from the fusion line increased. The ratio $G / V$ decreased from the fusion line toward the centerline [24]. This suggested that the solidification mode may change from planar to cellular and columnar dendritic across the fusion zone. At fusion line, the solidification rate $V$ was slow, and the grain grew with the planar mode along the easy-growth direction of the base-metal grain. A short distance away from the fusion line, solidification changes to the cellular mode, as shown in Fig. 2a. Figure 2b shows the surface morphology of the coating. The morphology presented a typical hypoeutectic structure, wherein the primary phase was fcc phase. The eutectic structure was a mixture of fcc phase and Laves phase that nucleated and grew alternately in the interdendritic regions. It constituted a continuous network structure of a white flower-shaped morphology, as marked by the arrows. The EDS results showed that the fcc solid solution phase was enriched in $\mathrm{Fe}$ and depleted in $\mathrm{Nb}$, while $\mathrm{Cu}$ depleted and $\mathrm{Nb}$ enriched for the Laves phase, as listed in Table 1. The reasons for this may ascribed to be following. On one hand, $\mathrm{Nb}$ has the largest atomic size in this alloy as well as very negative enthalpies of mixing with other alloying elements besides $\mathrm{Cu}$. That is not favorable to the solution of $\mathrm{Nb}$ into the fcc solid solutions and conversely enhances the tendency to form the ordered Nb-rich Laves phase. On the other hand, $\mathrm{Cu}$ and $\mathrm{Nb}$ have positive enthalpy of mixing (the value of $\mathrm{Cu}$ and $\mathrm{Nb}$ atomic pair is $5 \mathrm{~kJ} / \mathrm{mol}$ [25] ). Moreover, the binary phase diagrams between $\mathrm{Cu}$ and $\mathrm{Nb}$ show that phase separation is predicted across most of the composition range.

According to the Hume-Ruthery rule, to comprise the substitution solid solution, the atomic size difference between two incorporated elements should not be larger than $15 \%$, the lattice structure is similar to each other, and the electronegativity has no big difference. Accordingly, for the alloy series, besides the high entropy of mixing, the atomic size difference and the enthalpy of mixing of the incorporated elements cannot be ignored. The excellent work by Yeh et al. [1] has established that it is possible to form simple solid solutions when five or more than five elements are mixed in equi-atomic proportion. Subsequently, Yang and Zhang [26] have proposed solid solution criteria for multi-principle elemental HEAs. This work was mainly according to the equations in Ref. [26], and the 
Table 2 Enthalpies of mixing $\left(\Delta H_{\text {mix }}\right)$, entropies of mixing $\left(\Delta S_{\text {mix }}\right)$, $\Omega$ and atomic size difference $(\delta)$ for the $\mathrm{CoCrCuFeNiNb}$ coating

\begin{tabular}{llll}
\hline$\Delta H_{\text {mix }}(\mathrm{kJ} / \mathrm{mol})$ & $\Delta S_{\text {mix }}\left(10^{-3} \mathrm{~J} / \mathrm{mol}\right)$ & $\Omega$ & $\delta(\%)$ \\
\hline-5.89 & 14.90 & 4.86 & 5.16 \\
\hline
\end{tabular}

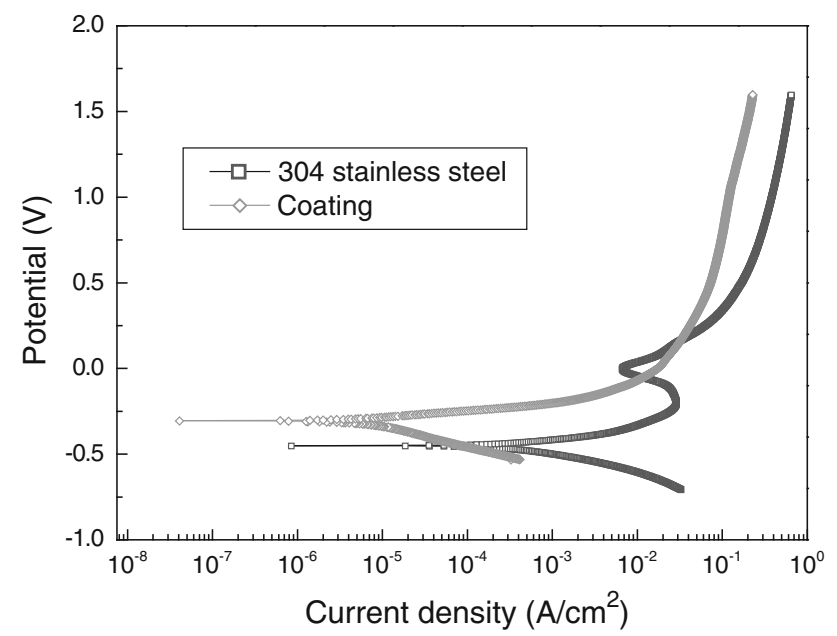

Fig. 3 Potentiodynamic polarization curves of the HEAs coating in comparison with $304 \mathrm{SS}$ in $1 \mathrm{~mol} / \mathrm{L}$ hydrochloric acid solution

corresponding results are listed in Table 2. According to Ref. [26], it is important to note that the specified solid solution criteria were satisfied by $\mathrm{CoNiCuFeCr}$ alloy systems. But for the $\mathrm{CoCrCuFeNiNb}$ alloy system, the value of $\Omega$ decreases, and the value of $\delta$ is relative large, indicating formation of solid solution phase and ordered phases. And these results were consistent with the XRD patterns and SEM morphologies.

\subsection{Potentiodynamic Polarization}

The potentiodynamic polarization curves of the coating and $304 \mathrm{SS}$ in $1 \mathrm{~mol} / \mathrm{L}$ hydrochloric acid solution are given in Fig. 3. Table 3 summarizes the relevant data. It can be seen that the coating had better overall general corrosion behavior, with a higher $E_{\text {corr }}$ and smaller $i_{\text {corr }}$ than those of 304 SS.

In general, the $i_{\text {corr }}$ can be used to calculate the general corrosion rate $\left(r_{\text {corr }}\right)$ of alloys. However, the corrosion rate is not only related to the corrosion current density but also to a function of atomic-fraction-weighted values of atomic weight, ion valence, and density of the alloy. Therefore, a more reasonable value of the $r_{\text {corr }}$ can be estimated according to Faraday's law as follows [27]:

$r_{\text {corr }}=0.00327 \frac{a i_{\text {corr }}}{n D}$,

where $a$ is the atomic weight, $i_{\text {corr }}$ is the corrosion current density $\left(\mu \mathrm{A} / \mathrm{cm}^{2}\right), n$ is the number of equivalents exchanged, and $D$ is the density $\left(\mathrm{g} / \mathrm{cm}^{3}\right)$. Calculation of correspondence between general corrosion rate and corrosion current density for an alloy requires a determination of the equivalent weight of the alloy, $a / n$, which is a weighted average of $a / n$ for the major alloying elements in any given alloy. The most popular method for calculation of equivalent weight sums the fractional number of equivalents of all alloying elements to determine the total number of equivalents, $N_{\mathrm{EQ}}$, which result from dissolving unit mass of the alloy [7]. That is,

$N_{\mathrm{EQ}}=\sum\left(\frac{f_{i}}{a_{i} / n_{i}}\right)=\sum\left(\frac{f_{i} n_{i}}{a_{i}}\right)$,

$a / n=1 / N_{\mathrm{EQ}}$,

where $f_{i}, n_{i}$ and $a_{i}$ are mass fraction, electrons exchanged, and atomic weight, respectively, of the $i$ th alloying element.

Calculation of equivalent weight for the non-equal mole, 6-component $\mathrm{CoCrCuFeNiNb} \mathrm{HEAs}$ coating assuming the following parameters for the alloy: $f_{\mathrm{Co}}=f_{\mathrm{Cr}}=f_{\mathrm{Cu}}=$ $f_{\mathrm{Fe}}=f_{\mathrm{Ni}}=f_{\mathrm{Nb}}=16.67$ at $\% ; \quad n_{\mathrm{Co}}=n_{\mathrm{Ni}}=n_{\mathrm{Cu}}=2$; $n_{\mathrm{Cr}}=n_{\mathrm{Fe}}=3 ; n_{\mathrm{Nb}}=5$. From Eq. (2),

$$
\begin{aligned}
N_{\mathrm{EQ}} & =\frac{0.1667 \times 5}{92.9}+\frac{0.1667 \times 2}{58.7}+\frac{0.1667 \times 2}{58.93} \\
& +\frac{0.1667 \times 3}{55.85}+\frac{0.1667 \times 3}{52}+\frac{0.1667 \times 2}{63.55}=0.0441 .
\end{aligned}
$$

Equivalent weight $(a / n)$ for the $\mathrm{CoCrCuFeNiNb}$ coating is 22.65. Similarly, a/n for $304 \mathrm{SS}$ is 25.12 . In addition, the densities of the $\mathrm{CoCrCuFeNiNb}$ coating and $304 \mathrm{SS}$ are 8.96 and $7.9 \mathrm{~g} / \mathrm{cm}^{3}$, respectively. Consequently, the general corrosion rate of the HEAs in $1 \mathrm{~mol} / \mathrm{L}$ hydrochloric acid solution was $0.08 \mathrm{~mm} / \mathrm{year}$, whereas that of $304 \mathrm{SS}$ was $7.58 \mathrm{~mm} / \mathrm{year}$. The $\mathrm{CoCrCuFeNiNb}$

\begin{tabular}{|c|c|c|c|c|c|c|}
\hline \multirow[t]{2}{*}{ Material } & \multicolumn{3}{|c|}{$1 \mathrm{~mol} / \mathrm{L}$ hydrochloric acid solution } & \multicolumn{3}{|c|}{$6 \mathrm{~mol} / \mathrm{L}$ hydrochloric acid solution } \\
\hline & $E_{\text {corr }}(\mathrm{V})$ & $i_{\text {corr }}\left(\mathrm{A} / \mathrm{cm}^{2}\right)$ & $r_{\text {corr }}(\mathrm{mm} /$ year $)$ & $E_{\text {corr }}(\mathrm{V})$ & $i_{\text {corr }}\left(\mathrm{A} / \mathrm{cm}^{2}\right)$ & $r_{\text {corr }}(\mathrm{mm} /$ year $)$ \\
\hline $\mathrm{CoCrCuFeNiNb}$ & -0.305 & $1 \times 10^{-5}$ & 0.08 & -0.397 & $8.93 \times 10^{-5}$ & 0.74 \\
\hline $304 \mathrm{SS}$ & -0.450 & $7.29 \times 10^{-4}$ & 7.58 & -0.426 & $2.07 \times 10^{-3}$ & 21.5 \\
\hline
\end{tabular}

Table 3 Electrochemical parameters of the CoCrCuFeNiNb HEAs coating and 304 SS in 1 and 6 mol/L hydrochloric acid solutions 


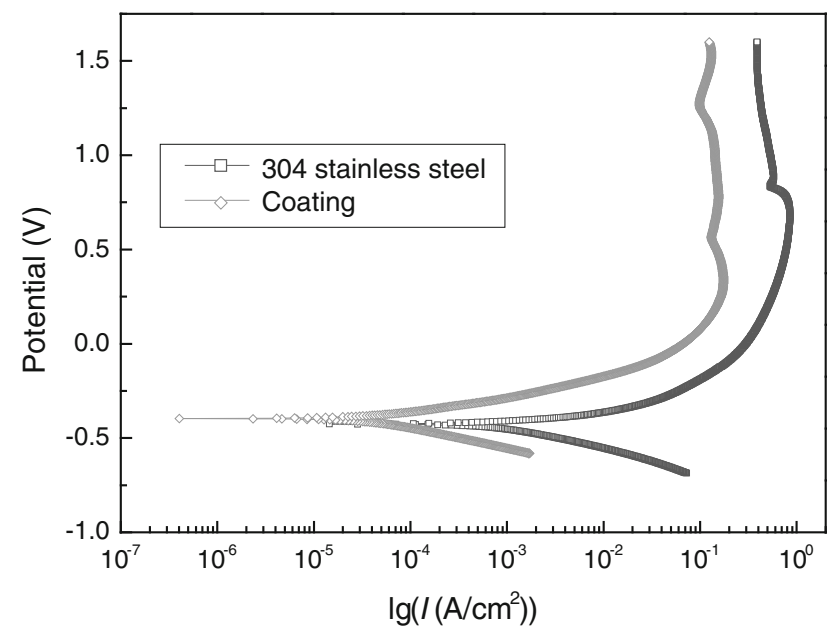

Fig. 4 Potentiodynamic polarization curves of the HEAs coating in comparison with $304 \mathrm{SS}$ in $6 \mathrm{~mol} / \mathrm{L}$ hydrochloric acid solution

HEAs coating had the higher resistance to general corrosion, i.e., uniform corrosion, than that of 304 SS.

Similar tests were also conducted in $6 \mathrm{~mol} / \mathrm{L}$ hydrochloric acid solution at room temperature. Figure 4 shows the potentiodynamic polarization curves of the HEAs coating and 304 SS. The coating exhibited excellent corrosion resistance indicating by low corrosion current density and wide passive region. In this electrolyte, the $E_{\text {corr }}$ for the HEAs coating $(-0.397 \mathrm{~V})$ was still higher than that for $304 \mathrm{SS}(-0.426 \mathrm{~V})$. And the corrosion current density for HEAs coating $\left(8.93 \times 10^{-5} \mathrm{~A} / \mathrm{cm}^{2}\right)$ was lower than that for $304 \mathrm{SS}\left(20.7 \times 10^{-4} \mathrm{~A} / \mathrm{cm}^{2}\right)$, as listed in Table 3 . In addition, the corrosion rate of the HEAs coating $(0.74 \mathrm{~mm} /$ year) was two orders of magnitude lower than that of $304 \mathrm{SS}$ (21.5 mm/year). It is apparent that the HEAs coating was more resistant to general corrosion in $6 \mathrm{~mol} / \mathrm{L}$ hydrochloric acid solution than 304 SS (higher $E_{\text {corr }}$, lower $i_{\text {corr }}$ and $\left.r_{\text {corr }}\right)$. On the other hand, it is worth noting that the corrosion rate of the HEAs coating in $1 \mathrm{~mol} / \mathrm{L}$ hydrochloric acid solution $(0.08 \mathrm{~mm} / \mathrm{year})$ was sharply lower than that in $6 \mathrm{~mol} / \mathrm{L}$ hydrochloric acid solution $(0.74 \mathrm{~mm} /$ year $)$, and the $E_{\text {corr }}$ value was nobler (see it in Table 3). It can therefore assume that a higher concentration of hydrochloric acid solution is more corrosive to the HEAs coating than a lower concentration. Similar to the results in $1 \mathrm{~mol} /$ $\mathrm{L}$ hydrochloric acid solution, the HEAs coating was also more resistant than $304 \mathrm{SS}$ to general corrosion in $6 \mathrm{~mol} / \mathrm{L}$ hydrochloric acid solution.

\subsection{Electrochemical Impedance Spectroscopy}

Figure 5 shows Nyquist plots for the HEAs coating and $304 \mathrm{SS}$ after $0.5 \mathrm{~h}$ immersion in $1 \mathrm{~mol} / \mathrm{L}$ hydrochloric acid

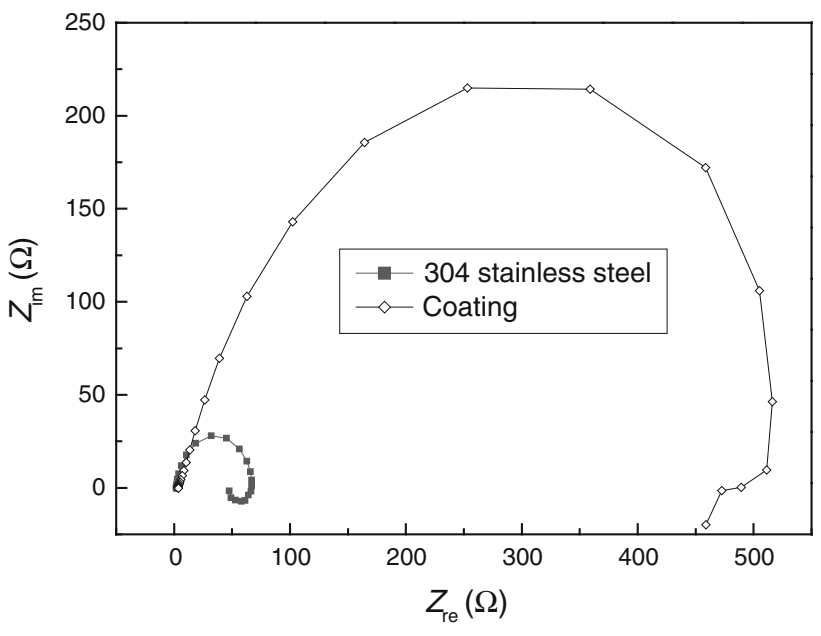

Fig. 5 Nyquist plots of impedance spectra of the HEAs coating and $304 \mathrm{SS}$ in $1 \mathrm{~mol} / \mathrm{L}$ hydrochloric acid solution

solution at open-circuit potential. Both Nyquist plots include one capacitive loop from high to medium frequencies and one inductive loop at low frequencies. According to Ref. [28, 29], this arc is related with metal dissolution in the corrosion process, which diameter is associated with charge-transfer resistance, i.e., corrosion resistance [30]. At the low frequencies, a second arc or tail in the Nyquist plots revealed an inductive behavior for all the samples, which correlated with the breakage of native corrosion produce film. It can be seen from Fig. 5 that the capacitive arc of the coating was significantly larger than that of 304 SS because of the formation of a passive film on the alloy coating. Therefore, the HEAs coating had excellent electrochemical behavior.

Figure 6 shows the equivalent electrical circuit which best fitted the experimental results, where $R_{\mathrm{S}}$ is the resistance of the solution; $R_{\mathrm{f}}$ means the charge transfer resistance; and $C_{\mathrm{f}}$ is the double-layer capacitance of the samples surface, which can be associated with the mechanism of the alloy dissolution and oxide (product of corrosion) film resistance; $L_{\mathrm{dl}}$ and $R_{\mathrm{ct}}$ are the inductance and the polarization resistance, respectively, which are intimately associated with the inductive loop occurring from 1 to $0.01 \mathrm{~Hz}$ (low frequency range) representing the pitting corrosion. The parameter " $n$ " is referred to the phase angle, varying between -1 and 1 . The impedance of a constant phase element was defined as $Z_{\mathrm{CPE}}=\left[C(j \omega)^{n}\right]^{-1}$, where $C$ is the capacitance, $j$ is the current density, $\omega$ is the frequency, and $-1 \leq n \leq 1$ [31]. The equivalent circuit was used to fit the experimental Nyquist plots of the coating and 304 SS by ZSimpwin commercial software (USA), in order to get the $R-C-L$ circuit parameters for the capacitive arc, especially the $R_{\mathrm{f}}$. The fit values are listed in Table 4. It indicated that 


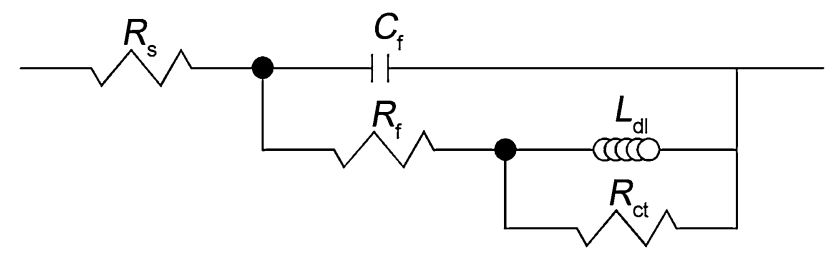

Fig. 6 EIS equivalent circuits for $304 \mathrm{SS}$ and the coating in $1 \mathrm{~mol} / \mathrm{L}$ hydrochloric acid solution

the $R_{f}$ values of the coating were evidently larger than the $304 \mathrm{SS}$ through the whole immersion periods in $1 \mathrm{~mol} / \mathrm{L}$ hydrochloric acid solution, i.e., corrosion resistance of the coating is better than that of 304 SS.

Figure 7 shows the Nyquist plots for the HEAs coating and $304 \mathrm{SS}$ after immersion in $6 \mathrm{~mol} / \mathrm{L}$ hydrochloric acid solution for $0.5 \mathrm{~h}$ at open-circuit potential. Similar experimental results were obtained for 304 SS. Moreover, for the HEAs coatings, a different behavior was observed, in that the electrochemical impedance diagrams included two capacitive loops which were typically related to the presence of an adsorption layer and charge transfer across the metal-electrolyte interface [32]. In addition, the capacitive arc of HEAs coating in $6 \mathrm{~mol} / \mathrm{L}$ hydrochloric acid solution was smaller than that in $1 \mathrm{~mol} / \mathrm{L}$ hydrochloric acid solution. It indicated that the HEAs coating has better corrosion resistance in lower concentration of hydrochloric acid solution. This was corresponding to the potentiodynamic polarization curves.

The equivalent electrical circuit of $304 \mathrm{SS}$ in $6 \mathrm{~mol} / \mathrm{L}$ hydrochloric acid solution was the same as the sample in $1 \mathrm{~mol} / \mathrm{L}$ hydrochloric acid solution, as shown in Fig. 6 . Figure 8 summarizes the equivalent circuit of the coatings in $6 \mathrm{~mol} / \mathrm{L}$ hydrochloric acid solution. In this equivalent circuit model, $R_{\mathrm{S}}$ is the solution resistance; $R_{\mathrm{ct}}$ and $R_{\mathrm{f}}$ are the resistances of the oxide and the coatings, respectively, which are associated to the charge transfer resistance through the oxide layer and the participation of adsorbed intermediates of the HEAs coatings; $C_{\mathrm{dl}}$ corresponds to the capacitance of the oxide layer and $C_{\mathrm{f}}$ to the capacitance of the coatings which seems to correspond to the double layer formation [31]. The fit values are also listed in Table 4. It can be seen that $R_{f}$ was $171.3 \Omega \mathrm{cm}^{2}$ for the coating, and declined to $12.05 \Omega \mathrm{cm}^{2}$ for $304 \mathrm{SS}$. Accordingly, the

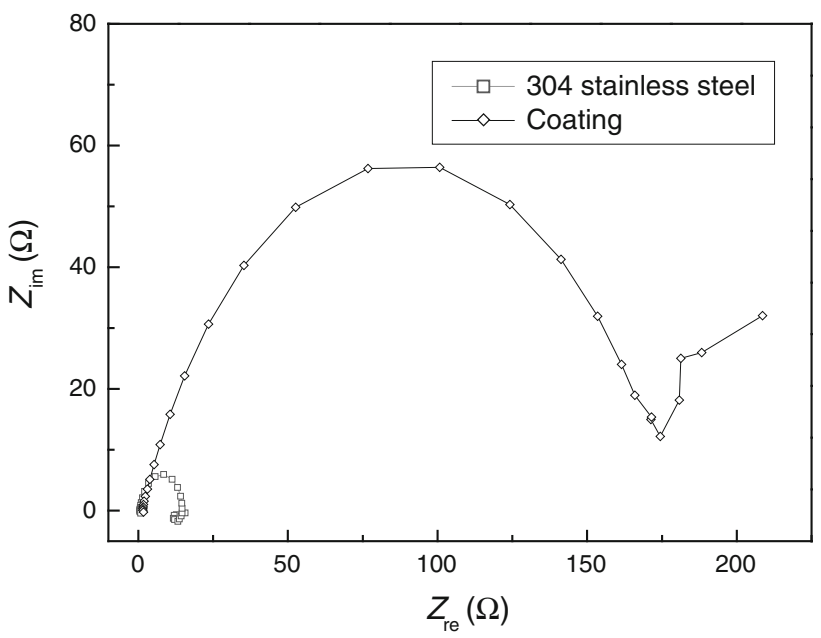

Fig. 7 Nyquist plots of the HEAs coating and 304 SS in $6 \mathrm{~mol} / \mathrm{L}$ hydrochloric acid solution

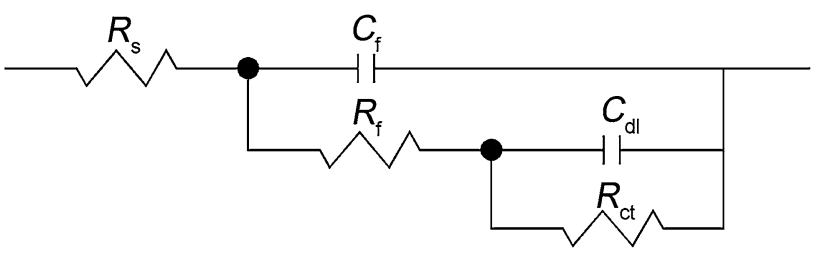

Fig. 8 The equivalent circuit for the coating in $6 \mathrm{~mol} / \mathrm{L}$ hydrochloric acid solution

$\mathrm{CoCrCuFeNiNb}$ coating displayed nobler corrosion resistance.

The improvement in the corrosion resistance of the $\mathrm{CoC}$ $\mathrm{rCuFeNiNb}$ coating could be attributed to its structure and the formation of very stable passive films due to the presence of $\mathrm{Nb}$. At first, low anode/cathode surface area ratio results in the galvanic corrosion between DR and ID. Electrochemical corrosion is initiated at the ID zone and propagates along the boundaries of the DR before finally forming DR and ID structures and even numerous corrosion pits. Second, compared with 304 SS, the high-entropy alloy coating had a lower Fe content and higher alloy elements content. The corrosion resistance of iron group alloys increased significantly with decreasing $\mathrm{Fe}$ content. In the corrosion solutions, $\mathrm{Fe}$ was dissolved preferentially. The additional $\mathrm{Cr}$ element was

Table 4 Fitted results for EIS of the coating and 304 SS in 1 and 6 mol/L hydrochloric acid solution

\begin{tabular}{llllccccc}
\hline Sample and solution & $R_{\mathrm{s}}\left(\Omega \mathrm{cm}^{2}\right)$ & $C_{\mathrm{f}}\left(\mu \mathrm{F} / \mathrm{cm}^{2}\right)$ & $n_{\mathrm{f}}$ & $R_{\mathrm{f}}\left(\Omega \mathrm{cm}^{2}\right)$ & $L_{\mathrm{dl}}(\mathrm{H})$ & $R_{\mathrm{ct}}\left(\Omega \mathrm{cm}^{2}\right)$ & $n_{\mathrm{dl}}$ & $C_{\mathrm{dl}}\left(\mu \mathrm{F} / \mathrm{cm}^{2}\right)$ \\
\hline 304 SS in 1 mol/L solution & 2.051 & 292.9 & 0.9089 & 46.51 & 50.78 & 18.72 & - & - \\
Coating in 1 mol/L solution & 2.323 & 691.8 & 0.7308 & 487.9 & 245 & 241 & - & - \\
304 SS in 6 mol/L solution & 0.6952 & 654.3 & 0.899 & 12.05 & 1.433 & 2.288 & - & - \\
Coating in 6 mol/L solution & 1.453 & 250.6 & 0.7391 & 171.3 & - & 105.1 & 0.7558 & 130.6 \\
\hline
\end{tabular}


considered as a strong film former that improved the corrosion resistance of alloys by forming hydrated chromium oxyhydroxide in passive films and effectively prevented the active dissolution of alloys. In addition, $\mathrm{Nb}$ forms very stable surface oxide films which were resistant at very high-oxidizing potentials, leading to their use in anodes for impressed current cathodic protection systems [33]. The formation of $\mathrm{NbO}$, $\mathrm{NbO}_{2}$, and $\mathrm{Nb}_{2} \mathrm{O}_{5}$ was identified according to the potential$\mathrm{pH}$ equilibrium diagram (Pourbaix) for $\mathrm{Nb}$ [34]. Moreover, the finer microstructure of the fcc phase formed by $\mathrm{Nb}$ addition provides excellent resistance against pitting in hydrochloric acid solution.

\section{Conclusions}

The CoNiCuFeCrNb HEAs coating was prepared by PTA cladding process. The formation of ordered Laves phase and fcc solid solution phase can be detected in the coating. Polarization curves indicated that HEAs coating is more resistant to general corrosion than 304 SS at room temperature in hydrochloric acid solution. The coating presents lower corrosion current and corrosion rates values than that of 304 SS. For EIS testing, the coating presents larger capacitive arc and higher fitted impedance $R_{\mathrm{f}}$ values than that of the as-cast $304 \mathrm{SS}$ in all concentrations testing.

Acknowledgments This work was financially supported by the National Natural Science Foundation of China (No. 51105129).

\section{References}

[1] J.W. Yeh, S.K. Chen, S.J. Lin, J.T. Gan, T.S. Chin, T.T. Shun, C.H. Tsau, S.Y. Chang, Adv. Eng. Mater. 6, 299 (2004)

[2] J.M. Zhu, H.M. Fu, H.F. Zhang, A.M. Wang, H. Li, Z.Q. Hu, Mater. Sci. Eng. A 527, 6975 (2010)

[3] M.H. Chuang, M.H. Tsai, W.R. Wang, S.J. Lin, J.W. Yeh, Acta Mater. 59, 6308 (2011)

[4] C.Y. Hsu, C.C. Juan, W.R. Wang, T.S. Sheu, J.W. Yeh, S.K. Chen, Mater. Sci. Eng. A 528, 3581 (2011)

[5] O.N. Senkov, G.B. Wilks, J.M. Scott, D.B. Miracle, Intermetallics 19, 698 (2011)

[6] M.H. Tsai, C.W. Wang, C.W. Tsai, W.J. Shen, J.W. Yeh, J.Y. Gan, J. Electrochem. Soc. 158, H1161 (2011)
[7] Y. Chen, T. Duval, U.D. Hung, J.W. Yeh, H.C. Shih, Corros. Sci. 47, 2257 (2005)

[8] T.K. Chen, T.T. Shun, J.W. Yeh, M.S. Wong, Surf. Coat. Technol. 188-189, 193 (2004)

[9] S.Y. Chang, S.Y. Lin, Y.C. Huang, Thin Solid Films 519, 4865 (2011)

[10] C.H. Lai, M.H. Tsai, S.J. Lin, J.W. Yeh, Surf. Coat. Technol. 201, 6993 (2007)

[11] C.H. Lin, J.G. Duh, J.W. Yeh, Surf. Coat. Technol. 201, 6304 (2007)

[12] H.W. Chang, P.K. Huang, A. Davison, J.W. Yeh, C.H. Tsau, C.C. Yang, Thin Solid Films 516, 6402 (2008)

[13] M.H. Tsai, C.H. Lai, J.W. Yeh, J.Y. Gan, J. Phys. D 41, 235402 (2008)

[14] P.K. Huang, J.W. Yeh, Scr. Mater. 62, 105 (2010)

[15] M.I. Lin, M.H. Tsai, W.J. Shen, J.W. Yeh, Thin Solid Films 518, 2732 (2010)

[16] P.K. Huang, J.W. Yeh, T.T. Shun, S.K. Chen, Adv. Eng. Mater. 6, 74 (2004)

[17] L.M. Wang, C.C. Chen, J.W. Yeh, S.T. Ke, Mater. Chem. Phys. 126, 880 (2011)

[18] J.H. Chen, P.N. Chen, C.M. Lin, C.M. Chang, Y.Y. Chang, WWu Surf, Coat. Technol. 203, 2983 (2009)

[19] H. Zhang, Y. Pan, Y.Z. He, H.S. Jiao, Appl. Surf. Sci. 257, 2259 (2011)

[20] H. Zhang, Y. Pan, Y.Z. He, Mater. Des. 32, 1910 (2011)

[21] X.Y. Ye, M.X. Ma, Y.X. Cao, W.J. Liu, X.H. Ye, Y. Gu, Phys. Proc. 12, 303 (2011)

[22] Y.J. Hsu, W.C. Chiang, J.K. Wu, Mater. Chem. Phys. 92, 112 (2005)

[23] J.B. Cheng, X.B. Liang, Z.H. Wang, B.S. Xu, Plasma Chem. Plasma Process. 33, 979 (2013)

[24] S. Kou, Welding Metallurgy, 2nd edn. (Wiley, Hoboken, 2003)

[25] F.R. De Boer, R. Boom, W.C.M. Mattens, A.R. Miedema, A.K. Niessen, Cohesion in Metals: Transition Metal Alloys (Elsevier Science Publishing Company. Inc., Amsterdam, 1989), pp. 65-225

[26] X. Yang, Y. Zhang, Mater. Chem. Phys. 132, 233 (2012)

[27] D.A. Jones, Principles and Prevention of Corrosion, 2nd edn. (Prentice Hall, Upper Saddle River, 1996)

[28] N. Pebere, C. Riera, F. Dabosi, Electrochim. Acta 35, 555 (1990)

[29] C. Cao, Electrochim. Acta 35, 837 (1990)

[30] C. Cao, Electrochim. Acta 35, 831 (1990)

[31] W.R. Osório, C. Brito, L.C. Peixoto, A. Garcia, Electrochim. Acta 76, 218 (2012)

[32] M.R.F. Hurtado, P.T.A. Sumodjo, A.V. Benedetti, Electrochim. Acta 48, 2791 (2003)

[33] B.X. Huang, K. Wang, J.S. Church, Y.S. Li, Electrochim. Acta 44, 2571 (1999)

[34] M. Pourbaix, Atlas of Electrochemical Equilibria in Aqueous Solutions (Pergamon Press, Oxford, 1966) 